\title{
Hypocapnia prolongs bradycardia induced by bupivacaine or levobupivacaine in isolated rat hearts
}

\author{
[L'hypocapnie prolonge la bradycardie provoquée par la bupivacaine ou la \\ lévobupivacaïne dans des caurs isolés de rats]
}

Toshiaki Mochizuki MD PhD, Shigehito Sato MD PhD

Purpose: Systemic alkalinization is recommended for resuscitation from local anesthetic-induced cardiotoxicity. It has been suggested that inducing hypocapnic alkalosis, prior to exposure to toxic concentrations of local anesthetics, may minimize cardiotoxicity. However, it remains unclear whether inducing severe hypocapnic alkalosis after administration of local anesthetics will minimize the duration of bradycardia. We used isolated rat hearts to investigate the effects of hypocapnic alkalosis on heart rate (HR) recovery from bupivacaine or levobupivacaineinduced bradycardia.

Methods: We measured the time required for the HR in 24 isolated rat hearts, respectively, to attain $90 \%$ of the baseline $H R$ (recovery time) following bradycardia induced by $1 \mu \mathrm{g} \cdot \mathrm{mL}^{-1}$ and $10 \mu \mathrm{g} \cdot \mathrm{mL}^{-1}$ concentrations of either bupivacaine or levobupivacaine. Normal pH perfusate (bupivacaine or levobupivacaine with normal $\mathrm{pH}$ washout groups) or severe hypocapnic alkalosis perfusate (bupivacaine or levobupivacaine with hypocapnic alkalosis washout groups) were reperfused after exposure to the local anesthetics.

Results: Severe hypocapnic alkalosis prolonged the recovery time from $273 \pm 122 \mathrm{sec}$, at the I $\mu \mathrm{g} \cdot \mathrm{mL}^{-1}$ bupivacaine concentration with normal pH washout, to $1203 \pm 540 \mathrm{sec}$, in the bupivacaine with hypocapnic alkalosis washout $(P=0.029)$. Severe hypocapnic alkalosis also prolonged the recovery time from $1153 \pm 644 \mathrm{sec}$, at a $10 \mu \mathrm{g} \cdot \mathrm{mL}^{-1}$ bupivacaine concentration in the normal $\mathrm{pH}$ washout group, to $2065 \pm 617 \mathrm{sec}$, in the bupivacaine with hypocapnic alkalosis washout group
$(P=0.032)$. With levobupivacaine $10 \mu \mathrm{g} \cdot \mathrm{mL}^{-1}$ in the normal $\mathrm{pH}$ washout group, HR recovery time increased from $863 \pm 186$ sec to $1565 \pm 567 \mathrm{sec}$, compared to the hypocapnic alkalosis washout group $(P=0.045)$.

Conclusions: Severe hypocapnic alkalosis prolonged the recovery time from bupivacaine or levobupivacaine-induced bradycardia in isolated rat hearts. When bradycardia occurs after intravascular bupivacaine or levobupivacaine administration, maintenance of normocapnia may minimize the duration of bradycardia.

CAN J ANESTH 2008/55: 12/pp 836-846

Objectif: L'alcalinisation systémique est recommandée pour la réanimation dans les cas de cardiotoxicité provoquée par un anesthésique local. Il a été suggéré que l'induction d'une alcalose hypocapnique avant l'exposition à des concentrations toxiques d'anesthésiques locaux pourrait minimiser la cardiotoxicité. Cependant, nous ne savons pas si l'induction d'une alcalose hypocapnique grave après l'administrotion d'anesthésiques locaux minimise la durée de la bradycardie. Nous avons utilisé des cœurs isolés de rats pour analyser les effets de l'alcalose hypocapnique sur le retour à une fréquence cardiaque (FC) normale à la suite d'une bradycardie provoquée par la bupivacaïne ou la lévobupivacaine.

From the Department of Anesthesiology and Intensive Care, Hamamatsu University School of Medicine, Hamamatsu, Shizuoka, Japan. Address correspondence to: Dr. Toshiaki Mochizuki, Department of Anesthesiology and Intensive Care, Hamamatsu University School of Medicine, 1-20-1 Handa-yama, Higashi-ward, Hamamatsu-city, Shizuoka-pref. 431-3192, Japan. Phone: ++81-53-435-2286; Fax: ++81-53-435-2284; E-mail: toshiaki@hama-med.ac.jp

Sources of financial support: Support was provided solely from institutional and departmental sources. Levobupivacaine was donated by Maruishi Pharmaceutical Co., Ltd, Osaka.

Conflicts of interest: None declared.

This work was presented, in part, at the 2004 annual meeting of the American Society of Anesthesiologists, Las Vegas, Nevada, October 25,2004 .

Accepted for publication March 25, 2008

Revision accepted July 2, 2008.

Final revision accepted August 12, 2008 
Méthode: Nous avons mesuré le temps requis pour que la FC de 24 cceurs isolés de rats atteigne $90 \%$ de la FC de base (temps de récupération) après une bradycardie provoquée par des concentrations de $1 \mu \mathrm{g} \cdot \mathrm{mL}^{-1}$ et $10 \mu \mathrm{g} \cdot \mathrm{mL}^{-1}$ de bupivacaine ou de lévobupivacaïne. Un perfusat au $\mathrm{pH}$ normal (groupes bupivacaïne ou lévobupivacaïne ovec solution de rinçage à $\mathrm{pH}$ normal) ou un perfusat d'alcalose hypocapnique sévère (groupes bupivacaïne ou lévobupivacaïne avec solution de rinçage alcaline hypocapnique) a été reperfusé après que les cœurs ont été exposés aux anesthésiques locaux.

Résultats: L'alcalose hypocapnique grave a prolongé le temps de récupération de $273 \pm 122 \mathrm{sec}$, à la concentration de bupivacaïne del $\mu \mathrm{g} \cdot \mathrm{mL}^{-1}$ ovec la solution de rinçage à $\mathrm{pH}$ normal, à $/ 203 \pm$ $540 \mathrm{sec}$, dans le groupe de bupivacaïne avec la solution de rinçage alcaline hypocapnique $(P=0,029)$. L'alcalose hypocopnique grave a également prolongé le temps de récupération de $1 / 53 \pm 644$ $\mathrm{sec}$, à une concentration de bupivacaïne $10 \mu \mathrm{g} \cdot \mathrm{mL}^{-1}$, à $2065 \pm 617$ sec dans le groupe de bupivacaïne avec solution de rinçage alcaline hypocapnique $(P=0,032)$. Avec de la lévobupivacaine $10 \mu \mathrm{g} \cdot \mathrm{mL}^{-1}$ dans le groupe à la solution de rinçage au $\mathrm{pH}$ normal, le temps de récupération de la fréquence cardiaque a augmenté de $863 \pm 186$ sec à $1565 \pm 567 \mathrm{sec}$, comparativement au groupe avec solution de lavage alcaline hypocapnique $(P=0,045)$.

Conclusion : L'alcalose hypocapnique a prolongé le temps de récupération après une bradycardie provoquée par la bupivacaïne ou la lévobupivacaïne dans des cœurs isolés de rats. Lorsque la bradycardie survient après l'administration intravasculaire de bupivacaïne ou de lévobupivacaïne, le maintien de la normocapnie pourrait minimiser la durée de la bradycardie.

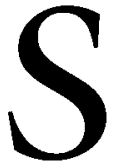
udden cardiovascular collapse has been reported to occur after accidental intravascular injection of potent local anesthetics, such as bupivacaine. ${ }^{1}$ Local anesthetics have been reported to cause bradycardia, as well as re-entrant arrhythmias, after intravascular administration..$^{2-4}$ Bupivacaine blocks many types of ion channels, including sodium channels. ${ }^{5,6}$ Accordingly, systemic alkalinization has been recommended to treat potentially fatal arrhythmias secondary to the effects of an overdose of sodium channel blocking agents. ${ }^{7}$ Furthermore, a canine study suggested that inducing hypocapnic alkalosis, prior to local anesthetic administration, ameliorates the electrocardiographic changes and the depression of cardiac contractility associated with ropivacaine overdose. ${ }^{8}$ Although bupivacaine is structurally similar to ropivacaine, it has long been known that the cardiodepressant effects and the electro-physiological toxicity induced by bupivacaine overdose are considerably more serious than the effects induced by high concentrations of ropivacaine. $^{9}$

In clinical practice, it has been recommended that systemic alkalinization should be induced by hypocapnic alkalosis after unintentional intravascular injection of local anesthetics. However, it remains unclear whether induction of hypocapnic alkalosis, after accidental parenteral administration of bupivacaine, exhibits any beneficial effect with regard to minimizing the duration of the recovery period from local anestheticinduced bradycardia. Accordingly, the purpose of this study was to compare the effects of hypocapnic alkalosis with the effects of its $S(-)$ isomer, levobupivacaine, on the duration of the recovery period resulting from bupivacaine-induced bradycardia in isolated rat hearts. We specifically tested the null hypothesis that the induction of hypocapnic alkalosis, after exposure to either bupivacaine or levobupivacaine, does not affect the recovery time from local anesthetic-induced $b$ radycardia.

\section{Materials and methods}

The Institutional Animal Care Committee of the Hamamatsu University School of Medicine approved all experimental procedures and protocols used in this study.

\section{Langendorff isolated heart preparation}

We used the Langendorff isolated rat heart preparation, as previously described, with minor modifications. ${ }^{10,11}$ Briefly, male Sprague-Dawley rats weighing 270 to $300 \mathrm{~g}$ were anesthetized with pentobarbital $\left(50 \mathrm{mg} \cdot \mathrm{kg}^{-1} \mathrm{ip}\right.$ ), and heparin was injected intravenously $\left(500 \mathrm{IU} \cdot \mathrm{kg}^{-1}\right)$. After each heart was isolated, the aorta was cannulated within one minute. The heart was then perfused at a constant pressure of approximately $70 \mathrm{~cm} \mathrm{H} \mathrm{H}_{2} \mathrm{O}$. A collapsed latex balloon LB-2 (Nihon Kohden, Tokyo, Japan) was inserted into the left ventricular $(\mathrm{LV})$ cavity via a left atrial incision, and the intra-balloon pressure was adjusted to 5-10 $\mathrm{mmHg}$. Each heart was allowed to beat spontaneously (unpaced) and was suspended inside a heated glass cylinder. We used a thermostatically-controlled waterjacketed system in which all glass reservoirs, the glass cylinder, and as many of the delivery lines as possible were surrounded by circulating water maintained at $37 \pm 0.5^{\circ} \mathrm{C}$ throughout the study. The LV pressure waveforms were continuously recorded. An electrocardiogram (ECG) was obtained by placing needle electrodes on the pulmonary artery, the right atrium, and the aortic root.

Heart rate (HR) was calculated as the reciprocal of each peak-to-peak interval of the LV pressure wave- 


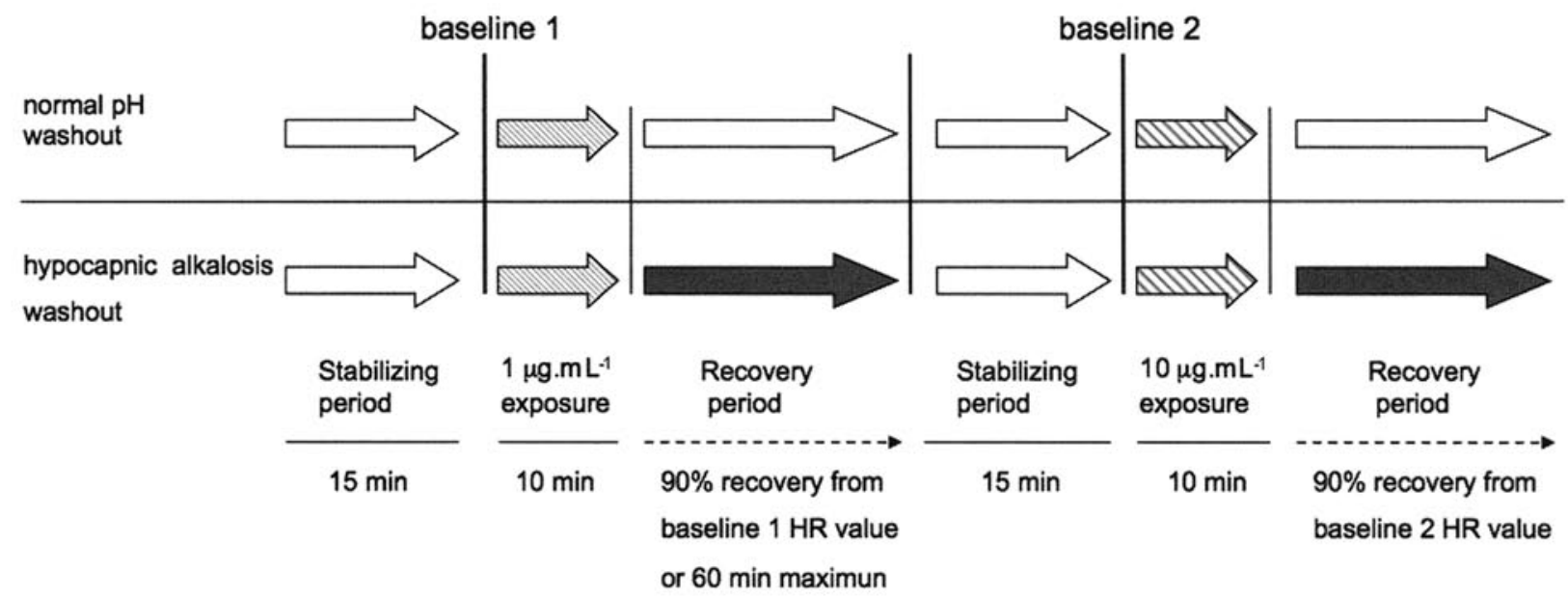

$\Longrightarrow$ normal $\mathrm{pH}$ perfusion $(\mathrm{pH}=7.35)$

$\Longrightarrow$ hypocapnic alkalosis perfusion $(\mathrm{pH}=7.55)$

$\Longrightarrow 1 \mu \mathrm{g} \cdot \mathrm{mL}^{-1}$ of bupivacaine or levobupivacaine in normal $\mathrm{pH}$ perfusate

$10 \mu \mathrm{g} \cdot \mathrm{mL}^{-1}$ of bupivacaine or levobupivacaine in normal $\mathrm{pH}$ perfusate

FIGURE 1 Study protocol.

forms. When no LV pressure waveform was observed within $60 \mathrm{sec}$, we regarded it as asystole; i.e., $\mathrm{HR}=0$. Coronary blood flow was measured at constant pressure and temperature was measured by a transit-time, in-line ultrasound flow meter (MFV 3200, Nihon Kohden, Tokyo, Japan). All signals were acquired using the PowerLab $4 / 20$ data acquisition system (AD Instrument Ltd, Castle Hill, Australia) and were stored in a computer. Data were analyzed off-line with Software Chart v4.2 (AD Instrument Ltd, Castle Hill, Australia).

The hearts were perfused with one of two types of modified Krebs-Henseleit buffers in $\mathrm{mmol} \cdot \mathrm{L}^{-1}: \mathrm{NaCl}$ $120, \mathrm{KCl} 4.7, \mathrm{MgCl}_{2} 1.24, \mathrm{CaCl}_{2}$ 1.27, $\mathrm{NaHCO}_{3} 20$, $\mathrm{KH}_{2} \mathrm{PO}_{4} 1.24$, glucose 11 . They were saturated with $95 \% \mathrm{O}_{2}+5 \% \mathrm{CO}_{2}, \mathrm{pH} 7.35$ maintained at $37 \pm 0.5^{\circ} \mathrm{C}$, defined as the normal $\mathrm{pH}$ perfusate, or were saturated with $95 \% \mathrm{O}_{2}+3 \% \mathrm{CO}_{2}+2 \% \mathrm{~N}_{2}, \mathrm{pH} 7.55$ maintained at $37 \pm 0.5^{\circ} \mathrm{C}$, defined as the hypocapnic alkalosis perfusate. Immediately before use, the $\mathrm{pH}$ and $\mathrm{pCO}_{2}$ values of the perfusate were measured by Stat profile $M$ (Nova Biochemical, MA, USA) from samples of continuously-aerated perfusate in the Langendorff apparatus via the connection port to the heart.
Investigations were undertaken in 24 isolated rat hearts. After initiation of coronary perfusion with the normal perfusate, a 15 -min stabilizing period was followed by ten minutes of exposure to local anesthetic at a final concentration of $1 \mu \mathrm{g} \cdot \mathrm{mL}^{-1}$ (low dose exposure period) in the normal $\mathrm{pH}$ perfusate. After the low dose exposure was concluded, either local anesthetic-free normal $\mathrm{pH}$ perfusate or local anesthetic-free hypocapnic alkalosis perfusate was reperfused from the time point immediately after exposure to the local anesthetic. The perfusates were continued until such time as either the HR (at normal sinus rhythm) reached approximately $90 \%$ of the báseline $H R$ value, as estimated in-line during the low-dose recovery period, or after a maximum of 60 min had elapsed. Subsequently, after an additional 15-min stabilization period with the normal $\mathrm{pH}$ perfusate, a ten-minute exposure to local anesthetic was performed (the same local anesthetic that was used during the low-dose exposure period with the normal $\mathrm{pH}$ perfusate) at a final concentration of 10 $\mu \mathrm{g} \cdot \mathrm{mL}^{-1}$ (high-dose exposure period). Likewise, the same $\mathrm{pH}$ local anesthetic-free perfusate, as was used during the low dose exposure period, was selected 
during the high dose recovery period (Figure 1). We used either bupivacaine $\mathrm{HCl}$ (bupivacaine; AstraZeneca Co., Ltd, Osaka, Japan) or levobupivacaine $\mathrm{HCl}$ (levobupivacaine; the $S(-)$ isomer of bupivacaine; Maruishi Pharmaceutical Co., Ltd, Osaka, Japan) for all experiments.

The isolated rat hearts were randomly allocated into one of four groups using a computer-generated randomization sequence: 1) bupivacaine with normal $\mathrm{pH}$ washout; 2) bupivacaine with hypocapnic alkalosis washout; 3) levobupivacaine with normal $\mathrm{pH}$ washout; and 4) levobupivacaine with hypocapnic washout (Figure 1). "Recovery time" was defined as the time period following local anesthetic exposure until the HR (at normal sinus rhythm) had attained $90 \%$ of the baseline HR value. After the experiments had been completed, a blinded observer recorded the recovery times off-line. Heart rate, coronary blood flows, and left ventricular systolic pressure (LVSP) were measured at the last minute of each of the stabilization periods (baseline), at each of the exposure periods, and at the "recovery times."

In a previous pilot study, we examined the duration of time for HR to attain $95 \%$ of the baseline HR value ( $95 \%$ recovery time) in both normal $\mathrm{pH}$ and hypocapnic washout groups following exposure to bupivacaine. The upper limits of the $95 \%$ confidence interval (CI) values at the $95 \%$ recovery times for the normal $\mathrm{pH}(n=3)$ and the hypocapnic alkalosis washout groups $(n=3)$ were $1123 \mathrm{sec}$ and 1836 sec, respectively. Therefore, we determined that the maximum recovery period was approximately twice the upper limit of the latter group of $1836 \mathrm{sec}$; i.e., $60 \mathrm{~min}$. In a separate pilot study, we found that, after high dose bupivacaine exposure, hypercapnic acidosis. reperfusion $\left(\mathrm{pH}=7.14\right.$ and $\mathrm{pCO}_{2}=52.7 \mathrm{mmHg}$ ) prolongs HR recovery times to more than $3600 \mathrm{sec}$ ( $n=2$, data not shown). Hence, we did not attempt to measure recovery times using the hypercapnic acidosis perfusate in this study.

Finally, to determine whether hypocapnic alkalosis affects coronary blood flow, independent of the effect of the cardiac toxicity induced by local anesthetics, six isolated hearts were perfused for $15 \mathrm{~min}$ with normal $\mathrm{pH}$ perfusate. Subsequently, the perfusate was switched to the hypocapnic alkalosis perfusate for ten minutes. Finally, reperfusion with normal $\mathrm{pH}$ perfusate was performed for $15 \mathrm{~min}$. Coronary blood flows were measured at the last minute of each period.

\section{Statistical analysis}

To test for differences in recovery times with or without hypocapnic alkalosis, in response to both the low

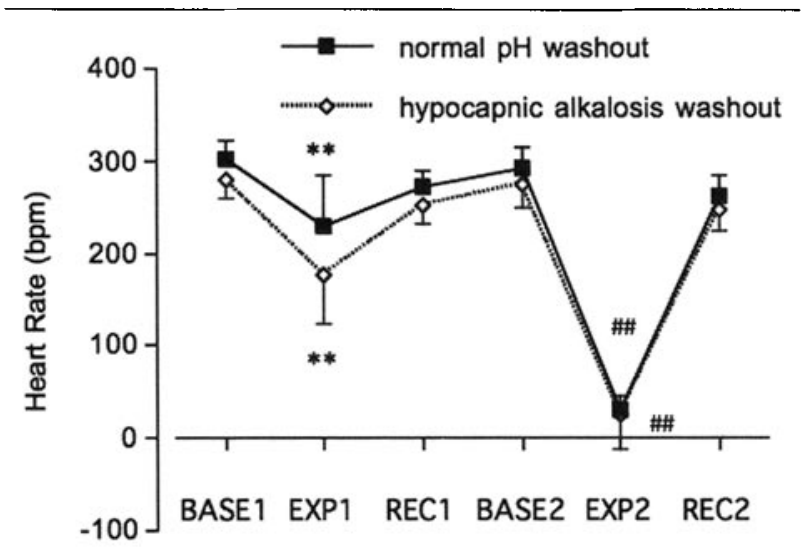

FIGURE 2 Changes in heart rate (HR) after exposure to bupivacaine. Low concentration $=1 \mu \mathrm{g} \cdot \mathrm{mL}^{-1}$ bupivacaine. High concentration $=10 \mu \mathrm{g} \cdot \mathrm{mL}^{-1}$ bupivacaine. Recovery time $=$ the time required for $H R$ to return to $90 \%$ of the baseline $H R$ value after local anesthetic exposure, as measured by a blinded observer, off-line. bpm $=$ beats $\cdot \mathrm{min}^{-1} ;$ BASEI $=$ baseline $1 ; \operatorname{EXPl}=$ low dose bupivacaine exposure; $\mathrm{RECl}$ = recovery time $1 ; \mathrm{BASE} 2$ = baseline 2; $\operatorname{EXP2}=$ high dose bupivacaine exposure; REC2 = recovery time 2. Two-way repeated measures ANOVA and Tukey HSD post hoc test. ${ }^{*}$ Significant $v$ s baseline 1 ; within group $(P<0.01)$. "Significant $p s$ baseline 2 ; within group $(P<0.01)$.

and high concentrations of local anesthetic exposure, and to evaluate changes of $\mathrm{HR}$, coronary blood flow, and LVSP, data were compared by two-way repeated measures analysis of variance (RMANOVA). To specify time points of differences when RMANOVA was significant $(P<0.05)$, we applied a Tukey HSD test, post hoc, using SPSS 15 J (SPSS Japan Inc., Tokyo, Japan). From a previous pilot study of three heart preparations, we found that the $90 \%$ upper one-sided confidence limit in recovery times, following low dose exposure to bupivacaine with normal $\mathrm{pH}$ washout, was approximately $400 \mathrm{sec}$ (sample size $=3$ ). We considered a minimal clinically important difference of treatment to be 600 sec; i.e., ten minutes. With $\alpha=0.05$ and $\beta=0.90$, the required sample size was five animals/heart preparations per group. To accommodate for potential dropouts or for incomplete studies, we selected a sample size of six animals per group. For these analyses, we used Excel 11.4 (Microsoft Corp., WA, USA) operating on a Macintosh OS X-based computer. Results in the text and figures are expressed as mean $\pm S D(C I)$, and statistical significance was assumed when $P<0.05$.

\section{Results}

The low and high concentrations of bupivacaine were associated with significant reductions in HR in both the bupivacaine with normal $\mathrm{pH}$ washout groups, 


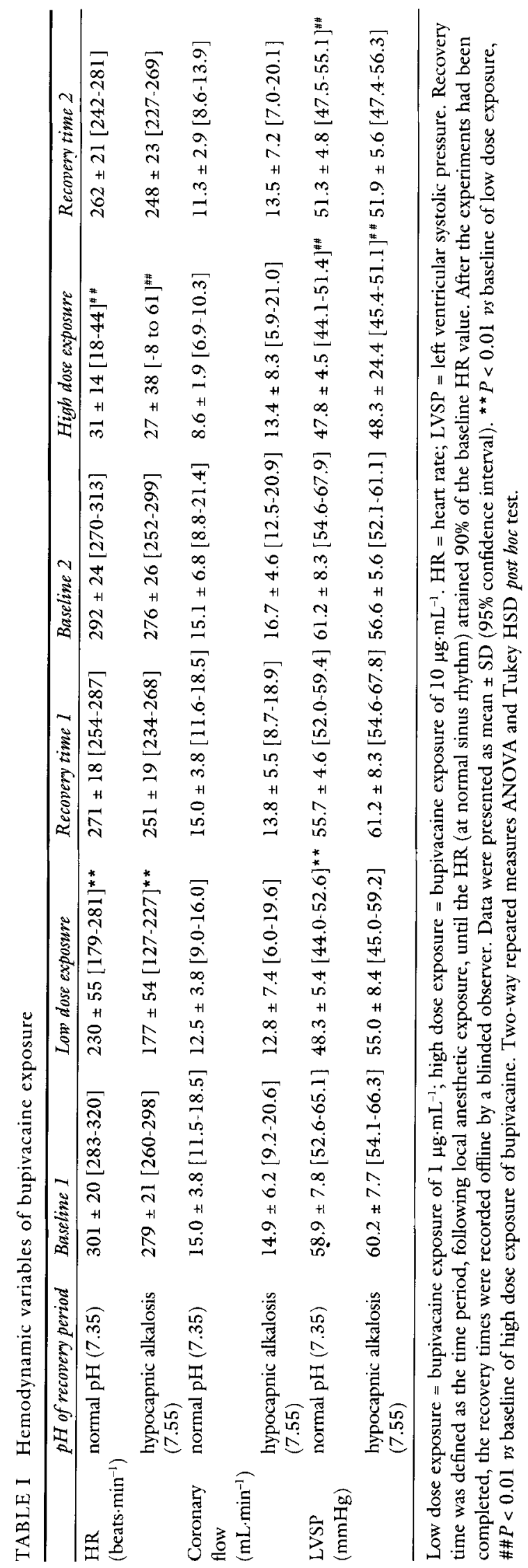




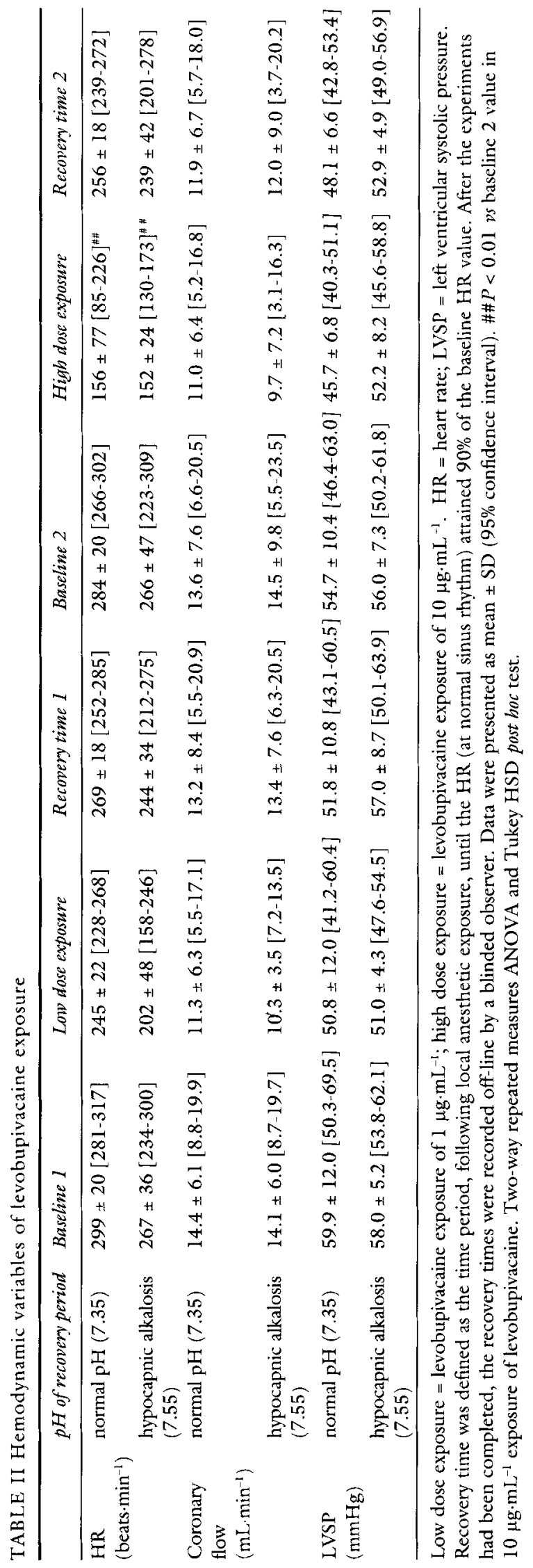




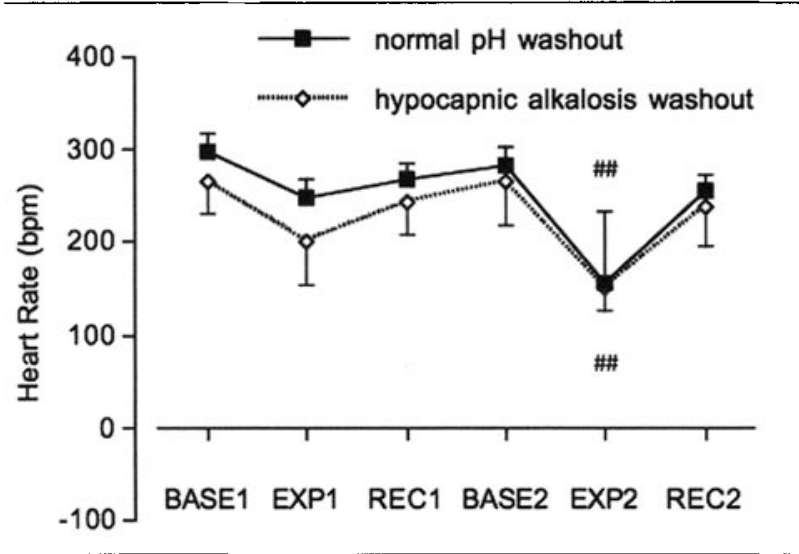

FIGURE 3 Changes in heart rate (HR) after exposure of levobupivacaine. Low concentration $=1 \mu \mathrm{g} \cdot \mathrm{mL}^{-1}$ bupivacaine. High concentration $=10 \mu \mathrm{g} \cdot \mathrm{mL}^{-1}$ levobupivacaine. Low concentration $=1 \mu \mathrm{g} \cdot \mathrm{mL}^{-1}$ levobupivacaine. High concentration $=$ $10 \mu \mathrm{g} \cdot \mathrm{mL}^{-1}$ levobupivacaine. Recovery time $=$ the time required for HR to return to $90 \%$ of the baseline HR value after local anesthetic exposure, as measured by a blinded observer, off-line. bpm = beats $\cdot \mathrm{min}^{-1} ; \mathrm{BASEl}=$ baseline $1 ; \mathrm{EXPl}=$ low dose levobupivacaine exposure; REC1 = recovery time $1 ; \mathrm{BASE} 2$ = baseline 2 ; EXP2

$=$ high dose levobupivacaine exposure; REC2 = recovery time 2 . Two-way repeated measures ANOVA and Tukey HSD post boc test. ${ }^{*}$ Significant $v$ baseline 2 ; within group $(P<0.01)$.

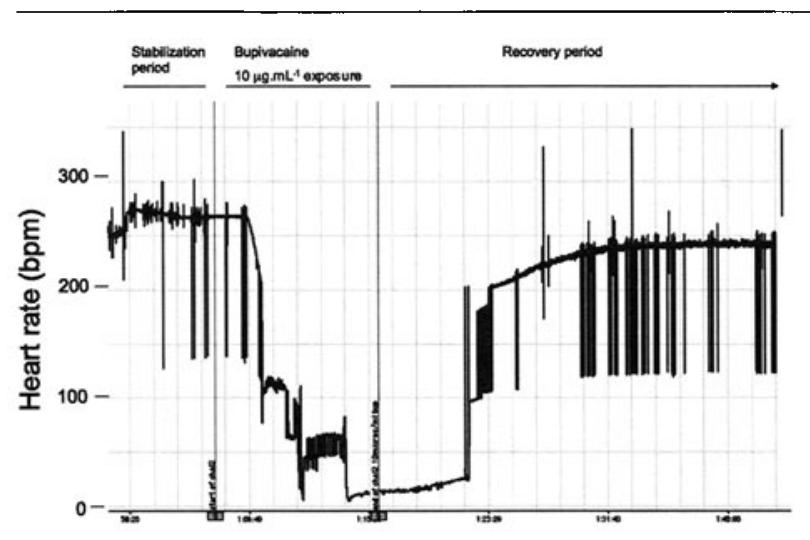

FIGURE 4 A representative HR trace of the stabilization period, high-dose local anesthetic exposure, and the recovery period of a case of bupivacaine with normal $\mathrm{pH}$ washout.

respectively ( $P=0.006$; Table I, Figure 2 ). The high dose of levobupivacaine reduced $\mathrm{HR}$ in the levobupivacaine with normal $\mathrm{pH}$ washout group (Table II, Figure 3). Figure 4 shows representative HR tracings during the stabilization period following high dose bupivacaine exposure and during the recovery period following bupivacaine with normal $\mathrm{pH}$ washout.

At both the low and the high concentrations of bupivacaine, hypocapnic alkalosis significantly pro-

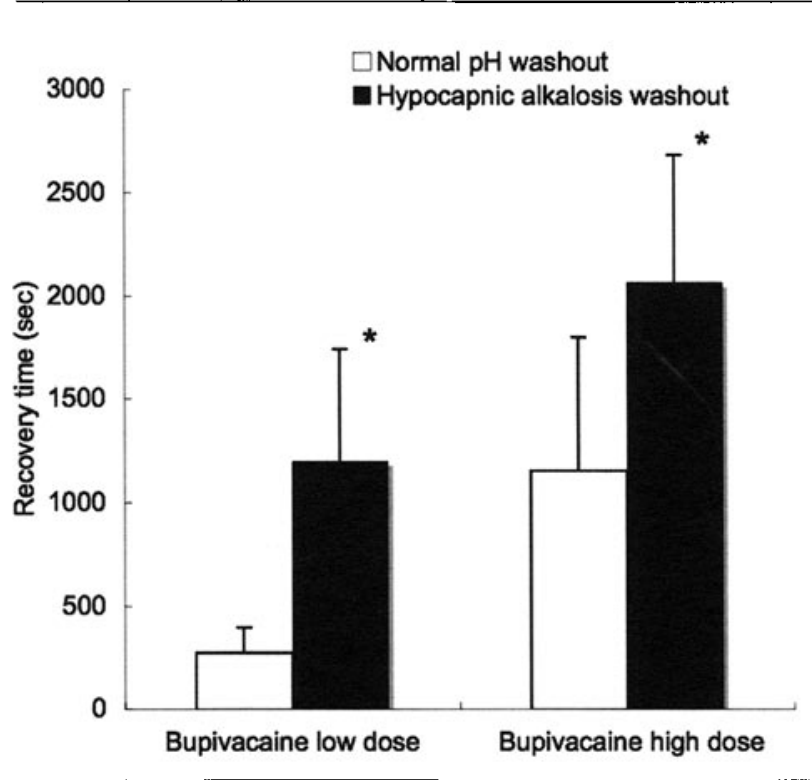

FIGURE 5 Hypocapnic alkalosis washout after exposure to 1 $\mu \mathrm{g} \cdot \mathrm{mL}^{-1}$ (low concentration) and $10 \mu \mathrm{g} \cdot \mathrm{mL}^{-1}$ (high concentration) bupivacaine significantly prolonged the recovery times. ${ }^{*} P<0.05$ $p s$ normal $\mathrm{pH}$ washout group, by two-way repeated measures ANOVA followed by Tukey HSD post hoc test.

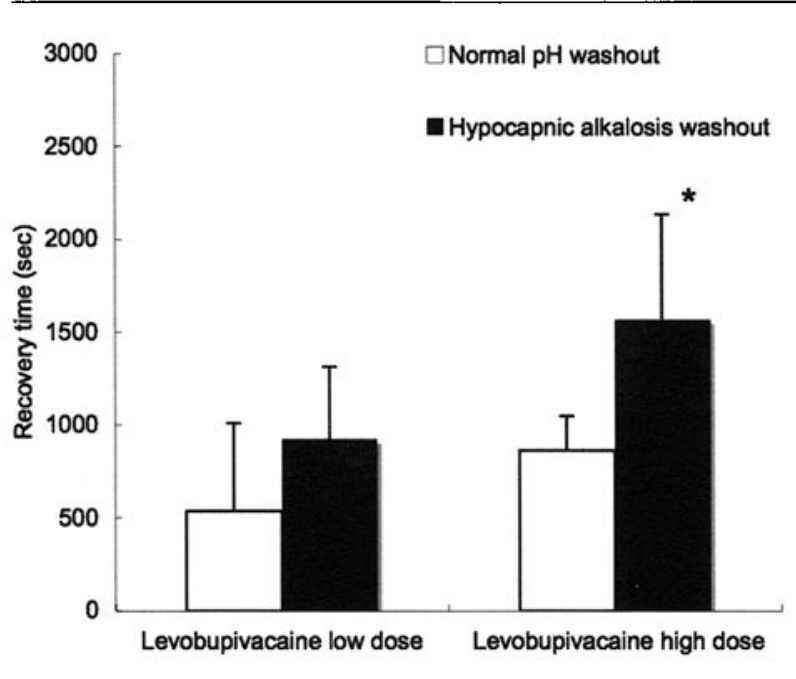

FIGURE 6 Hypocapnic alkalosis washout after exposure to $10 \mu \mathrm{g} \cdot \mathrm{mL}^{-1}$ (high concentration) levobupivacaine significantly prolonged the recovery times. The low-dose was defined as a final local anesthetic concentration of $1 \mu \mathrm{g} \cdot \mathrm{mL}^{-1}$. ${ }^{*} P<0.05 v$ n normal $\mathrm{pH}$ washout group by two-way ANOVA followed by Tukey HSD post hoc test.

longed the mean HR recovery times (Figure 5 ). Similarly, at the high concentration of levobupivacaine, hypocapnic alkalosis prolonged HR recovery times 
TABLE III $\mathrm{pH}$ and $\mathrm{pCO}_{2}$ of the perfusate used in recovery period

\begin{tabular}{lll}
\hline Perfusate & $p H$ & $p \mathrm{CO}_{2}$ \\
\hline Bupivacaine with normal $\mathrm{pH}$ washout $(n=6)$ & $7.36 \pm 0.04[7.33-7.40]$ & $36.2 \pm 3.9 \mathrm{mmHg}[33.0-39.3]$ \\
Bupivacaine with hypocapnic alkalosis washout $(n=6)$ & $7.55 \pm 0.03[7.53-7.57]$ & $20.9 \pm 0.9 \mathrm{mmHg}[20.2-21.7]$ \\
Levobupivacaine with normal $\mathrm{pH}$ washout $(n=6)$ & $7.36 \pm 0.04[7.33-7.39]$ & $38.2 \pm 1.2 \mathrm{mmHg}[37.3-39.2]$ \\
Levobupivacaine with hypocapnic alkalosis washout $(n=6)$ & $7.54 \pm 0.03[7.51-7.56]$ & $20.8 \pm 0.6 \mathrm{mmHg}[20.4-21.2]$ \\
\hline
\end{tabular}

Values are mean \pm SD $(95 \%$ confidence interval).

(Figure 6). Coronary blood flows remained similar within groups (Tables I, II). The lower concentrations of local anesthetic exposure did not prolong the recovery time beyond $60 \mathrm{~min}$ in any group for any heart preparation. The $\mathrm{pH}$ and $\mathrm{pCO}_{2}$ values of the perfusates are presented in Table III.

No spontaneous tachyarrhythmias were observed in any heart preparation. Transient Mobitz type II cardiac conduction defects were observed in $10 / 12$ and $2 / 12$ hearts during exposure to the high concentrations of bupivacaine and levobupivacaine, respectively. Idioventricular rhythms were observed in $8 / 12$ hearts during the exposure to high concentration bupivacaine. Asystole was observed in $1 / 12$ hearts exposed to bupivacaine. All hearts spontaneously reverted to normal sinus rhythm during the recovery period.

Finally, hypocapnic alkalosis reduced coronary blood flow from $11.7 \pm 2.3 \mathrm{~mL} \cdot \mathrm{min}^{-1}$ (CI 9.4-14.0 $\left.\mathrm{mL} \cdot \mathrm{min}^{-1}\right)$, after the initial normal $\mathrm{pH}$ perfusion $(n=$ 6 ), to $8.9 \pm 2.2 \mathrm{~mL} \cdot \mathrm{min}^{-1}$ (CI $6.7-11.1 \mathrm{~mL} \cdot \mathrm{min}^{-1}$ ), after the hypocapnic alkalosis perfusion $(n=6)$; i.e., resulting in an attenuation to $76 \%$ of the initial normal pH perfusion $(P<0.001$, Figure 5$)$.

\section{Discussion}

This laboratory investigation demonstrated that the HR recovery times, following bupivacaine or levobupivacaine-induced bradycardia, were prolonged when conditions of hypocapnic alkalosis were applied.

Bupivacaine blocks the fast sodium channels and slows conduction through calcium and potassium channels. ${ }^{12}$ However, bupivacaine altered coronary blood flow at a concentration of $3 \mu \mathrm{g} \cdot \mathrm{mL}^{-1}$ in an isolated rat heart model with constant coronary perfusion pressure. ${ }^{13}$ Conversely, in the current investigation, we did not detect significant differences in coronary blood flow with time. Since the time intervals between local anesthetic exposure and the "recovery time" were somewhat variable between experiments, the effects of the local anesthetic and $\mathrm{pH} / \mathrm{pCO}_{2}$ ratios of perfusate to coronary blood flow at each time point may have been subject to fluctuations, while hypocapnic

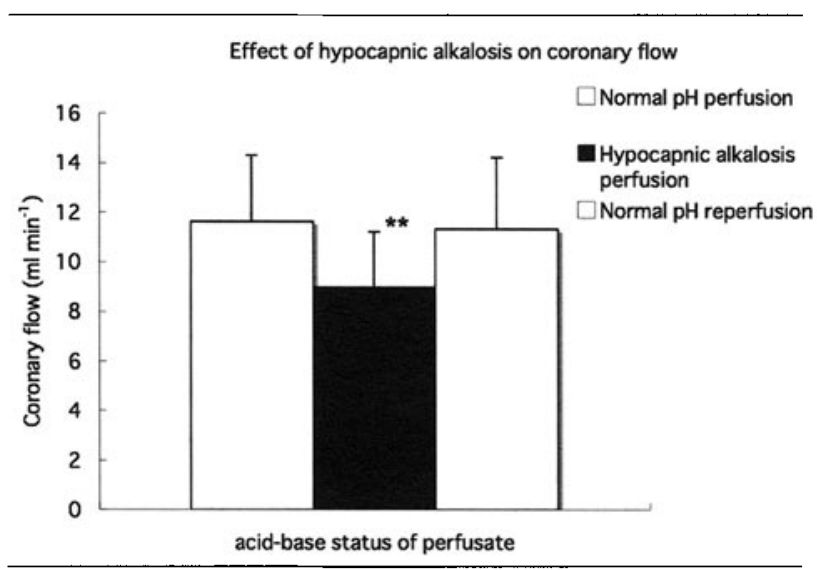

FIGURE 7 Effect of hypocapnic alkalosis on coronary blood flow. Coronary blood flow was reduced by $76 \%$ during the hypocapnic alkalosis perfusion period. ${ }^{\star \star} P<0.001$ vs initial normal $\mathrm{pH}$ perfusion by one-way repeated measures ANOVA followed by Tukey post hoc test.

alkalosis decreases coronary blood flow independently (Figure 7). Any decrease in coronary blood flow induced by hypocapnic alkalosis would retard the local anesthetic washout from myocardium during the local anesthetic-free washout period. Moreover, since $\mathrm{CO}_{2}$ molecules shift rapidly via the cellular membrane, ${ }^{14}$ hypocapnic alkalosis might increase the intracellular $\mathrm{pH}$ of the cardiomyocytes in our study. This might have accelerated the binding of bupivacaine or levobupivacaine to ion channel proteins, thus prolonging the bradycardia induced by bupivacaine or levobupivacaine. Further study is warranted to investigate these potential mechanisms.

Porter $e t a l .^{8}$ have suggested that hypocapnic alkalosis improves the ECG changes and cardiac contractility induced by amide local anesthetics. However, in their laboratory investigation, hypocapnic alkalosis was induced prior to loading of the local anesthetics. ${ }^{8}$ Under conditions of hypocapnic alkalosis prior to loading of local anesthetics, intracellular $\mathrm{pH}$ would be increased compared with normal $\mathrm{pH}$ conditions, 
due to $\mathrm{CO}$, molecules rapidly shifting via the cellular membrane. ${ }^{14}$ Therefore, when hypocapnic alkalosis is induced prior to loading of local anesthetics, the amount of intracellular local anesthetic that shifts from the systemic circulation - which could potentially affect ion channel proteins - would be decreased compared to conditions at physiological $\mathrm{pH}$.

Bupivacaine has been reported to impair conduction of electrical impulses in isolated mammalian hearts. ${ }^{2,15}$ On the other hand, bupivacaine exhibited reverse frequency-dependent depression of contractility in isolated mammalian papillary muscles. ${ }^{6}$ The reverse frequency-dependent depression of contractility of bupivacaine suggests that myocardial contractility might be restored when HR was reduced by secondary to bupivacaine toxicity. Ultimately, when administered intraveneously to animals in vivo, bupivacaine appeared to reduce $\mathrm{HR}$ and cardiac output. ${ }^{16}$ However, in a model of isolated unpaced hearts under constant coronary perfusion pressure, after bupivacaine exposure at a concentration that corresponded to our study, local anesthetic-free washout restored all hemodynamic variables, including $\mathrm{HR}$ and LV contractile force. ${ }^{13}$ Therefore, we regarded $H R$ as a critical variable when we evaluated the recovery by local anesthetic-free washout following cardiotoxic doses of bupivacaine and levobupivacaine.

In our study, hypocapnic alkalosis prolonged recovery times at a low concentration of bupivacaine. On the other hand, hypocapnic alkalosis did not prolong recovery times at a low concentration of levobupivacaine (Figures 5,6 ). The bupivacaine used in our study consisted of dextrobupivacaine and levobupivacaine as enantiomers. It has been reported that recovery from sodium channel blockade is faster with levobupivacaine compared to dextrobupivacaine. ${ }^{17}$ Since recovery from the chronotropic cardiotoxicity of local anesthetics was assumed to be faster with levobupivacaine compared to bupivacaine, hypocapnic alkalosis would not have affected recovery times when exposed to low concentrations of levobupivacaine under our experimental model.

Based on their animal studies, several investigators reported that cardiac resuscitation, following bupivacaine-induced toxicity, is difficult under hypoxic and acidotic conditions. ${ }^{18,19}$ In a pilot study, we found that hypercapnic acidosis $(\mathrm{pH}=7.14$ and $\mathrm{pCO}_{2}=52.7$ ) remarkably prolonged the cardiac recovery period. Taken together, these findings suggest that hypercapnic acidosis should be avoided when recovery is attempted following bupivacaine cardiac toxicity.
In clinical practice, hypercapnic acidosis tends to occur following accidental intravenous administration of local anesthetics, including bupivacaine. ${ }^{1}$ To treat bupivacaine- or levobupivacaine-induced cardiac toxicity, we recommend that either severe hypocapnic alkalosis; i.e., $\mathrm{pCO}_{2} \leq 20 \mathrm{mmHg}$ or hypercapnic acidosis should be avoided. Instead, it is essential to maintain normocapnia during recovery from bupivacaine- or levobupivacaine-induced bradycardia. Although "moderate" hypocapnia; i.e., $\mathrm{pCO}_{2}$ of approximately $30 \mathrm{mmHg}$, can be seen in clinical settings, we did not examine the influence of this "moderate" hypocapnic level on recovery times in this study. Additionally, several recent reports illustrate the potential benefit of intravenous infusion of lipid emulsion; i.c., "lipid rescue," for treating bupivacaine-induced cardiac arrest that was refractory to standard cardiopulmonary resuscitation. ${ }^{20,21}$ It remains unclear which $\mathrm{pCO}_{2}$ range should be recommended before or during the "lipid rescue" to have a maximum effect towards successful recovery from bupivacaine-induced cardiovascular collapse.

The Langendorff isolated perfused rat heart preparation has limitations in the assessment of recovery from local anesthetic exposure. The hearts are denervated during the isolation process. In this model, spontaneous HR and coronary blood flow differ from the in vivo situation. On the other hand, isolating the heart has important advantages, including the assessment of coronary and myocardial effects, the evaluation of preparation controls for the influence of altered systemic hemodynamics, such as preload and afterload, and the appraisal of changes in the humoral and autonomic nervous systems. We selected a blood and protein-free perfusate to ensure the maintenance of stable local anesthetic perfusate concentrations. The $\mathrm{pH}$, electrolyte, glucose, and perfusate gas concentrations can also be maintained at constant levels, and continuous administration of anesthetics is not necessary. Finally, the target concentration of local anesthetics in the perfusate could be easily manipulated and/or kept constant.

Although we maintained the intra-balloon pressure at $5-10 \mathrm{mmHg}$, it has been recommended that LV end diastolic pressure would be adjusted to 4-8 $\mathrm{mmHg}$ at the beginning of the study in the isolated heart models. ${ }^{22}$ The volume of the latex balloons to measure $\mathrm{LV}$ pressure parameters were relatively small in relation to the LV cavity of the isolated rat hearts used in this study. As a result, the initial LV end-diastolic volumes which we recorded might not 
have reached a sufficient size to reflect the initial $\mathrm{LV}$ contractile force parameters described in a previous study. ${ }^{23}$ Although the HR values were derived from peak-to-peak intervals of LV pressure waveforms for convenience, the baseline HR values were consistent with previous reports. ${ }^{22}$ Furthermore, the primary concern of our study was not to measure the absolute values of $\mathrm{LV}$ pressure parameters, but to measure the changes of the HR recovery in response to several interventions. Thus, the findings of our study should have implications relevant to the clinical setting.

In summary, compared with HR recovery at nor$\mathrm{mal} \mathrm{pH}$, severe hypocapnic alkalosis prolonged the period of HR recovery following bupivacaine- or levobupivacaine-induced bradycardia, in the isolated perfused rat heart model. Our data suggest that, it may be beneficial, when treating bradycardia following accidental intravascular injection of bupivacaine or levobupivacaine, to maintain normocapnia to minimize the duration of bradycardia. Further investigation is warranted to recommend a specific range for carbon dioxide regulation during resuscitation from local-anesthetic induced cardiotoxicity.

\section{References}

1 Albright $G A$. Cardiac arrest following regional anesthesia with etidocaine or bupivacaine.

Anesthesiology 1979; 51: 285-7.

2 Lacombe $P$, Blaise $G$, Loulmet D, Hollmann $C$. Electrophysiologic effects of bupivacaine in the isolated rabbit heart. Anesth Analg 1991; 72: 62-9.

3 Bruelle $P$, Lefrant J , de La Coussaye JE, et al. Comparative electrophysiologic and hemodynamic effects of several amide local anestheric drugs in anesthetized dogs. Anesth Analg 1996; 82: 648-56.

4 de La Coussaye JE, Bassoul BP, Albat B, et al. Succinylcholine does not worsen bupivacaine-induced cardiotoxicity in pentobarbital-anaesthetized dogs. Can J Anaesth 1992; 39: 192-7.

5 Clarkson $C W$, Hondeghem $L M$. Evidence for a specific receptor site for lidocaine, quinidine and bupivacaine associated with cardiac sodium channels in guinea pig ventricular myocardium. Circ Res 1985; 56: 496-506.

6 Lynch C $3^{r d}$. Depression of myocardial contractility in vitro by bupivacaine, etidocaine and lidocaine. Anesth Analg 1986; 65: 551-9.

7 American Heart Association. 2005 American Heart Association Guidelines for Cardiopulmonary Resuscitation and Emergency Cardiovascular Care. Part 10.2: Toxicology in emergency cardiovascular care. Circulation 2005; 112(suppl IV): IV-128-30.
8 Porter JM, Markos F, Snow HM, Shorten GD. Effects of respiratory and metabolic $\mathrm{pH}$ changes and hypoxia on ropivacaine-induced cardiotoxicity in dogs. $\mathrm{Br}$ J Anaesth 2000; 84: 92-4.

9 Reiz $S$, Haggmark $G$, Johansson $G$, Nath $S$. Cardiotoxicity of ropivacaine-a new amide local anaesthetic agent. Acta Anaesthesiol Scand 1989; 33: 93-8.

10 Okada H, Kurita T, Mochizuki T, Morita K, Sato S. The cardioprotective effect of dexmedetomidine on global ischaemia in isolated rat hearts. Resuscitation 2007; 74: 538-45.

11 Hui $\Upsilon$, Mochizuki T, Kondo K, Umemura K, Sato $S$. Nitric oxide donor, NOC7, reveals biphasic effect on contractile force of isolated rat heart after global ischemia. J Anesth 2008; 22: 229-35.

12 Heavner JE. Cardiac toxicity of local anesthetics in the intact isolated heart model: a review. Reg Anesth Pain Med 2002; 27: 545-55.

13 Tanz RD, Heskett T, Loebning $R W$, Fairfax CA. Comparative cardiotoxicity of bupivacaine and lidocaine in the isolated perfused mammalian heart. Anesth Analg 1984; 63: 549-56.

14 Bromage PR, Burfoot MF, Crowell DE, Truant AP. Quality of epidural blockade. III. Carbonated local anaesthetic solutions. Br J Anaesth 1967; 39: 197-209.

15 Moller RA, Covino BG. Cardiac electrophysiologic effects of lidocaine and bupivacaine. Anesth Analg 1988; 67: 107-14.

16 Liu P, Feldman HS, Covino BM, Giasi R, Covino BG. Acute cardiovascular toxicity of intravenous amide local anesthetics in anesthetized ventilated dogs. Anesth Analg 1982; 61: 317-22.

17 McLeod GA, Burke D. Levobupivacaine. Anaesthesia $2001 ; 56: 331-41$.

18 Rosen MA, Thigpen JW, Shnider SM, Foutz SE, Levinson $G$, Koike $M$. Bupivacaine-induced cardiotoxicity in hypoxic and acidotic sheep. Anesth Analg 1985; 64: 1089-96.

19 Sage DJ, Feldman HS, Arthur GR, et al. Influence of lidocaine and bupivacaine on isolated guinea pig atria in the presence of acidosis and hypoxia. Anesth Analg 1984; 63: 1-7.

20 Rosenblatt $M A$, Abel $M$, Fischer GW, Itzkovich CJ, Eisenkraft JB. Successful use of a $20 \%$ lipid emulsion to resuscitate a patient after a presumed hbupivacainerelated cardiac arrest. Anesthesiology 2006; 105 : 217-8.

21 Weinberg $G$. Lipid infusion resuscitation for local anesthetic toxicity: proof of clinical efficacy. Anesthesiology 2006; 105: 7-8.

22 Sutherland FJ, Hearse DJ. The isolated blood and 
perfusion fluid perfused heart. Pharmacol Res 2000; 41: 613-27.

23 Stehr SN, Pexa $A$, Hannack $S$, et al. Insulin effects on myocardial function and bioenergetics in L-bupivacaine toxicity in the isolated rat heart. Eur J Anaesthesiol 2007; 24 : 340-6.

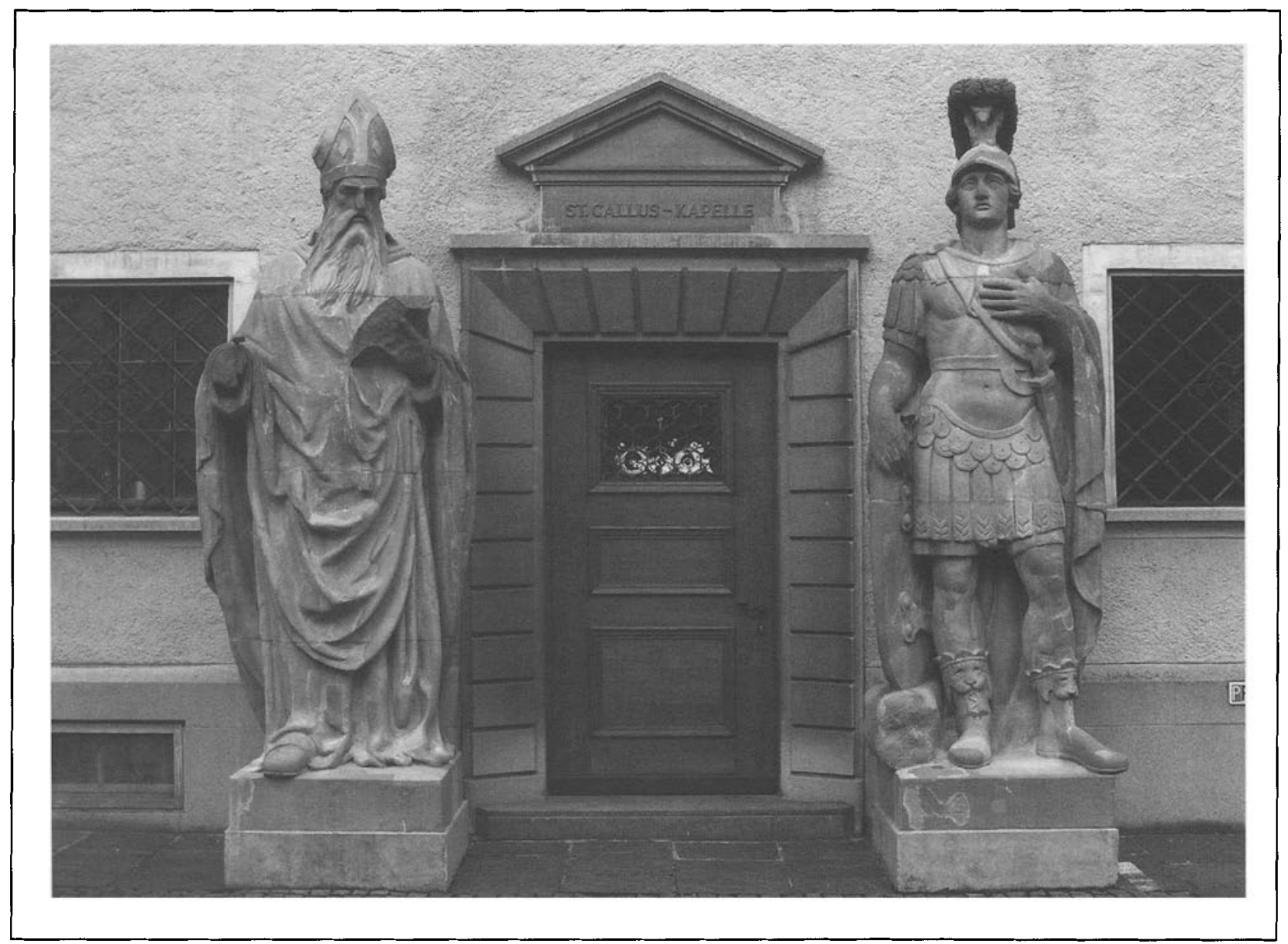

Chapel at St. Gallen, Switzerland 